University of Nebraska - Lincoln

DigitalCommons@University of Nebraska - Lincoln

Faculty Papers and Publications in Animal

Science

Animal Science Department

January 2003

\title{
Correlated response in placental efficiency in swine selected for an index of components of litter size
}

\author{
H. Mesa \\ University of Missouri, Columbia \\ T. J. Safranski \\ University of Missouri, Columbia \\ R. K. Johnson \\ University of Nebraska-Lincoln, rjohnson5@unl.edu \\ W. R. Lamberson \\ University of Missouri, Columbia
}

Follow this and additional works at: https://digitalcommons.unl.edu/animalscifacpub

Part of the Animal Sciences Commons

Mesa, H. ; Safranski, T. J.; Johnson, R. K.; and Lamberson, W. R., "Correlated response in placental efficiency in swine selected for an index of components of litter size" (2003). Faculty Papers and Publications in Animal Science. 58.

https://digitalcommons.unl.edu/animalscifacpub/58

This Article is brought to you for free and open access by the Animal Science Department at DigitalCommons@University of Nebraska - Lincoln. It has been accepted for inclusion in Faculty Papers and Publications in Animal Science by an authorized administrator of DigitalCommons@University of Nebraska - Lincoln. 


\title{
Correlated response in placental efficiency in swine selected for an index of components of litter size $e^{1,2}$
}

\author{
H. Mesa*3, T. J. Safranski*, R. K. Johnson $\dagger$, and W. R. Lamberson*4 \\ *Department of Animal Science, University of Missouri, Columbia 65211 and \\ $\dagger$ Department of Animal Science, University of Nebraska, Lincoln 68583
}

\begin{abstract}
The objective of this study was to evaluate correlated response in placental efficiency to selection for components of litter size. Fourteen generations of selection had resulted in a difference between lines of three fully formed piglets at birth. Gilts from a line selected for an index of components of litter size (S, n $=33)$ and a randomly selected control $(\mathrm{C}, \mathrm{n}=27)$ were observed at farrowing. At delivery, the umbilical cord of each piglet was double tagged with identically numbered mouse ear tags to allow the piglet's weight to be matched to the corresponding placental weight. Litter size, placental weight, birth weight, and placental vascularity were recorded. Litter size was higher $(12.0 \pm 0.7$ vs $7.9 \pm 0.7)$ in $\mathrm{S}$ than in $\mathrm{C}(P<0.001)$. Line differences in placental vascularity were not significant with or without adjustment for litter size $(P=0.45$ and 0.39 ,
\end{abstract}

respectively). Correlated response to selection for components of litter size resulted in a reduced birth weight (S $82.6 \%$ of $\mathrm{C}, P<0.001$ ) and a reduced placental weight (S 90.9\% of C, $P=0.11$ ). After adjusting for litter size, line differences in neither placental weight nor birth weight were significant $(P=0.40$ and 0.07 , respectively), which indicates that the reduction in birth weight was, for the most part, due to the increase in litter size. The result of the difference in the magnitude of the change for both weights was that placental efficiency, measured as the ratio of birth weight:placental weight was 0.43 higher in $\mathrm{C}(P=0.05)$. Adjustment for litter size increased the difference in placental efficiency to 0.52 $(P=0.02)$. Since a significant difference in litter size favoring the selected line was observed, we hypothesize that this physiological response was achieved through mechanisms other than improved placental efficiency.

Key Words: Litter Size, Pigs, Placenta, Selection

(O)2003 American Society of Animal Science. All rights reserved.

J. Anim. Sci. 2003. 81:74-79

\section{Introduction}

Much effort has been devoted to the improvement of litter size in swine due to its impact on productive and economic efficiency. Different selection strategies can be implemented emphasizing one or several of the physiological components of litter size (ovulation rate, embryo survival, and fetal survival) or traits correlated with them (Johnson et al., 1985). Ovulation rate can be increased by selection (Lamberson et al., 1991) or by

\footnotetext{
${ }^{1}$ This research was supported in part by the Missouri Agric. Exp. Stn. and contributed to the objectives of the NC-220 Regional Research Program.

${ }^{2}$ This project was partially funded by the National Pork Board on behalf of the Missouri Pork Producers Association.

${ }^{3}$ Supported by a COLCIENCIAS-FULBRIGHT-LASPAU program scholarship.

${ }^{4}$ Correspondence: 159 Animal Sciences Center, 920 E. Campus Dr. (phone: 573-882-8234; fax: 573-884-7827; E-mail: LambersonW@ missouri.edu).

Received March 10, 2002.

Accepted August 22, 2002.
}

management and exogenous gonadotrophin treatments (Longenecker and Day, 1968; Fenton et al., 1970), although the effect on litter size at parturition is limited.

Under conditions of adequate quantity and quality of semen and accurate timing of insemination, fertilization rate is greater than $95 \%$ and embryonic mortality is 20 to $30 \%$ (reviewed by Pope, 1994). The number of embryos present after the losses associated with fertilization failure and embryo death has been termed potentially viable embryos (Bennett and Leymaster, 1989). Fetal survival is affected by uterine capacity, defined as the maximal number of fetuses a female can carry to term when the number of potentially viable embryos is not limiting (Bennett and Leymaster, 1989). Uterine capacity is considered dependent on uterine size, nutrient and gaseous exchange, and placental surface area (Webel and Dziuk, 1974).

Index selection, which included ovulation rate and embryonic survival, produced a difference of three fully formed piglets at birth (Johnson et al., 1999). In a separate experiment, one generation of divergent selection for placental efficiency, measured as the ratio of birth weight:placental weight, yielded a difference in litter 
size of 2.5 piglets (Wilson et al., 1999). Although the latter experiment was very small, the remarkable response suggests that placental efficiency has an important role in determining litter size. The objective of this study was to evaluate correlated response in placental efficiency to selection for components of litter size.

\section{Materials and Methods}

Gilts from a randomly selected control $(\mathbf{C}, \mathrm{n}=27)$ and a line selected for components of litter size $(\mathbf{S}, \mathrm{n}=$ 33) were observed at farrowing. Procedures and response to 14 generations of selection were presented by Johnson et al. (1999). Briefly, selection was practiced for eleven generations on an index including the number of corpora lutea (OR) and embryonic survival (ES), measured as the ratio of fetuses:OR at $50 \mathrm{~d}$ of gestation. From generations 12 to 14, selection was practiced for an increased number of fully formed pigs at parturition. Differences between $\mathrm{C}$ and $\mathrm{S}$ at generation 14 were three fully formed pigs $(P<0.01)$ and 1.4 live pigs $(P$ $<0.05)$ per litter.

In the present experiment, the umbilical cord of each piglet was double tagged with identically numbered mouse ear tags at parturition. One tag was placed approximately $5 \mathrm{~cm}$ and the other $10 \mathrm{~cm}$ from the piglet. The cord was severed between the tags and the piglet weighed. All placentas were collected and weighed at delivery. Approximately 33\% of the placentas were not tagged because the umbilical cord ruptured during the process or the piglet was already detached from it at birth. Information collected included litter size (LS), birth weight (BW), placental weight (PW), dam prefarrowing weight (PFW), and maternal grandsire identification of the litter (MGS). Placental efficiency (PE) was calculated as the ratio of BW:PW. In a subset of placentas, placental vascularity (PV) was subjectively scored from 1 to 5 , where 1 = minimal vascularization.

Statistical analyses were performed using the GLM, REG, and CORR procedures of SAS (SAS Inst., Inc., Cary, NC). The effects of index selection on litter average $(\mathrm{n}=60) \mathrm{BW}, \mathrm{PW}, \mathrm{PE}$, and PV were analyzed using a model including line, maternal PFW, and litter MGS nested within line, with and without LS as covariate. Litter size was analyzed as a maternal trait using a model including line and litter MGS nested within line. Litter MGS nested within line was used as the error term to test line effects in all models. The number of MGS represented per line was 13 in $\mathrm{C}$ and 15 in $\mathrm{S}$. The standard errors of line means are underestimated since they do not account for genetic drift. Regression analyses of BW on PW were performed and tested for heterogeneity of regression between lines (Wilcox et al., 1990). Correlation coefficients among the traits studied were calculated and compared in the general population and within each line.

\section{Results}

Litter size, calculated as the number of fully formed piglets at birth, was four piglets higher in $\mathrm{S}$ than $\mathrm{C}(P$ $<0.001$, Table 1).

When LS was not included as a covariate in the model, BW was $214 \mathrm{~g}$ higher in $\mathrm{C}$ than $\mathrm{S}(P<0.001)$. Inclusion of LS in the model reduced the difference in $\mathrm{BW}$ to $94 \mathrm{~g}$ in favor of $\mathrm{C}(P=0.07)$. Line differences in $\mathrm{PW}$ were not significant with or without litter size as a covariate in the model $(P=0.40$ and $P=0.11$, respectively).

Placental efficiency was always higher in C than S. When LS was not included as a covariate in the model, the difference was $0.43(P=0.05)$. Inclusion of LS in the model increased the difference to $0.52(P=0.02)$. Placental vascularity did not differ between lines either including or not including LS in the model $(P=0.44$ and 0.39 , respectively).

The regression of $\mathrm{BW}$ on $\mathrm{PW}$ was curvilinear in both lines $(P<0.0001$, Figure 1$)$. The test for heterogeneity of regression determined that this curvilinear relationship was the same in both lines $(P>0.05)$ with differences in the intercept originating from differences in the mean BW for each line. Placental vascularity was not significantly correlated with $\mathrm{PW}$ or $\mathrm{PE}$ at the population level or within $\mathrm{C}$ and $\mathrm{S}(P>0.50)$. A significant negative correlation was observed between $\mathrm{PW}$ and $\mathrm{PE}$ at the population level and within $\mathrm{C}$ and $\mathrm{S}(\mathrm{r}=-0.54$, -0.70 , and -0.53 , respectively; $P<0.0001$ ).

\section{Discussion}

The results of the present study show that the selection practiced in these lines on components of litter size resulted in significant changes in BW and PE (Table 1). Selection for higher litter size decreased BW, whereas PW, though numerically lower in S, was statistically not different between lines. The net result was that PE, measured as the ratio of these two weights, was higher in the control line.

Litter size is predicted to increase by improving any of its components when the other components are not limiting (Bennett and Leymaster, 1989). The responses observed after 11 generations of selection in this population were 7.4 ova and 3.8 fetuses at $d 50$, which yielded 2.3 fully formed pigs at birth (Johnson et. al. 1999). The loss of 1.5 potential piglets between d 50 and birth suggests that as ovulation rate and the quantity of embryos present increase, uterine capacity becomes more limiting. Studies using unilateral hysterectomy-ovariectomy suggested that placental insufficiency is the primary mechanism through which intrauterine crowding of fetuses decreases fetal survival and growth (Knight et al., 1977). The three additional generations of direct selection for litter size in the population prior to this experiment may have resulted in an increase in uterine capacity, as suggested by a reduction in the number of mummified fetuses from 0.70 per litter in generation 
Table 1. Least squares means ( \pm SEM) line differences in birth weight, placental weight, placental efficiency, and placental vascularity with and without litter size (LS) as a covariate in the model

\begin{tabular}{|c|c|c|c|c|c|c|c|c|c|}
\hline \multirow[b]{2}{*}{ Line } & \multirow[b]{2}{*}{$\begin{array}{c}\text { Litter } \\
\text { size }\end{array}$} & \multicolumn{2}{|c|}{ Birth weight } & \multicolumn{2}{|c|}{ Placental weight } & \multicolumn{2}{|c|}{ Placental efficiency } & \multicolumn{2}{|c|}{ Placental vascularity } \\
\hline & & $\begin{array}{c}\text { LS } \\
\text { covariate }\end{array}$ & $\begin{array}{c}\text { No } \\
\text { covariate }\end{array}$ & $\begin{array}{c}\text { LS } \\
\text { covariate }\end{array}$ & $\begin{array}{c}\text { No } \\
\text { covariate }\end{array}$ & $\begin{array}{c}\text { LS } \\
\text { covariate }\end{array}$ & $\begin{array}{c}\text { No } \\
\text { covariate }\end{array}$ & $\begin{array}{c}\mathrm{LS} \\
\text { covariate }\end{array}$ & $\begin{array}{c}\text { No } \\
\text { covariate }\end{array}$ \\
\hline \multirow{3}{*}{ Control } & 7.94 & 1164.62 & 1233.54 & 209.14 & 227.43 & 5.81 & 5.71 & 3.17 & 2.96 \\
\hline & $(0.71)$ & (34.32) & (36.67) & (8.81) & (9.14) & $(0.17)$ & $(0.15)$ & $(0.53)$ & $(0.29)$ \\
\hline & 11.99 & 1070.48 & 1019.15 & 220.33 & 206.71 & 5.29 & 5.28 & 2.38 & 2.59 \\
\hline Selected & $(0.67)$ & (30.96) & $(34.65)$ & (7.95) & (8.63) & $(0.14)$ & $(0.15)$ & $(0.54)$ & $(0.29)$ \\
\hline
\end{tabular}

11 to 0.47 in generation 14 (Johnson et al., 1999). This is supported by the prediction of Bennett and Leymaster (1990) that mass selection for litter size puts more emphasis on the more limiting trait, uterine capacity in this case.

Uterine capacity has been defined in terms of the number of embryos or fetuses the female can support at any stage (Bazer et al., 1969; Fenton et al., 1970; Christenson et al., 1987), total litter weight at parturition (van Oijen et al., 1993), or the total amount of placental mass or surface area a female can carry to term (Wilson et al., 1999). Uterine capacity was found to be dependent on insemination weight of the sow (van Oijen et al., 1993). The physiological mechanisms involved in the control of uterine capacity are still not fully determined. The description of uterine capacity as being dependent on uterine space, nutrient and gaseous exchange, and placental surface proposed by Webel and Dziuk (1974) allows some refinement. Three categories can be identified in the components of uterine capacity: uterine, placental, and fetal.

Uterine agents include protein secretion (Bazer et al., 1991; Vallet, 2000), blood flow (Ford and Christenson, 1979; Ford, 1995), endometrial vascularization (Biensen et al., 1999), and space or volume, assumed to be dependent on length and diameter of the uterine horns (Gama and Johnson, 1993). Crossbreeding experiments with Meishan and Large White pigs provided examples of how uterine capacity could be increased using different physiological strategies in different populations; breed differences are attributed to factors not related to uterine size, whereas heterosis effects result from greater uterine size (Lee et al., 1995).

Placental agents include total exchange surface (Leiser and Dantzer, 1988), efficiency of the placental transfer mechanisms (Sibley and Boyd, 1988), and vascularization (Ford, 1997; Wilson et al., 1998; Biensen et al., 1999). Knight et al. (1977) found that fetal weight was strongly associated with placental traits such as placental length, surface area, total areolae surface, and weight $(\mathrm{r}=0.64,0.72,0.65$, and 0.74 , respectively, $P<0.01)$; whereas placental weight alone as a predictor of fetal weight was as good as any combination of the other placental variables measured. Placental surface is positively correlated with placental weight $(\mathrm{r}=0.82$, $P<0.001$; Biensen et al., 1998).
Fetal agents include the absolute demand for nutrients and the ability of the fetus to direct an increase in the supply of these nutrients, especially during the last half of gestation. The reduced growth rate of Meishan fetuses relative to fetuses from western breeds at all stages is likely to decrease the demands for nutrients (Christenson, 1993; Wilson et al., 1998).

Reduced growth rates of Meishan conceptuses have both a uterine environment and a fetal component. Reciprocal transfer of embryos between Meishan and Yorkshire demonstrated that at d 12, Meishan embryos are smaller than Yorkshire embryos, and that embryos transferred to a Meishan uterus are smaller than those in a Yorkshire uterus (Youngs et al., 1994). Similar results were found at d 30 comparing Meishan and Landrace $\times$ Large White females (Ashworth et al., 1990). Meishan and Yorkshire embryos cotransferred into either Meishan or Yorkshire uteri demonstrated that at d 90, all fetuses and placentas were smaller when recovered from Meishan vs Yorkshire recipients; fetuses were similar in weight in a Meishan recipient, and Meishan fetuses were lighter than Yorkshire littermates in a Yorkshire recipient (Wilson et al., 1998). All these studies indicate that in addition to an inherent slower growth rate of the Meishan conceptus, the Meishan uterine environment has an inhibitory effect on conceptus growth, probably through limitations to placental growth.

A second mechanism used by the Meishan breed to achieve higher uterine capacity is the fetal ability to direct an increase in placental vascularization instead of increasing placental size during the last third of gestation, when fetal demands increase dramatically (Ford, 1997). When Yorkshire and Meishan littermates gestate to term in a Yorkshire recipient, there is no difference in piglet weight, but Meishan placentas are smaller and present increased vascularization (Wilson et al., 1998). The ratio of fetal weight:placental weight, a measurement of placental efficiency, is then higher in Meishan conceptuses. Biensen et al. (1999) concluded that uterine factors determine conceptus size, and that conceptus genotype controls placental efficiency via increased vascularization.

Uterine capacity of the selected line in the present study might have increased by changes in uterine space, as it has been reported that when the number 

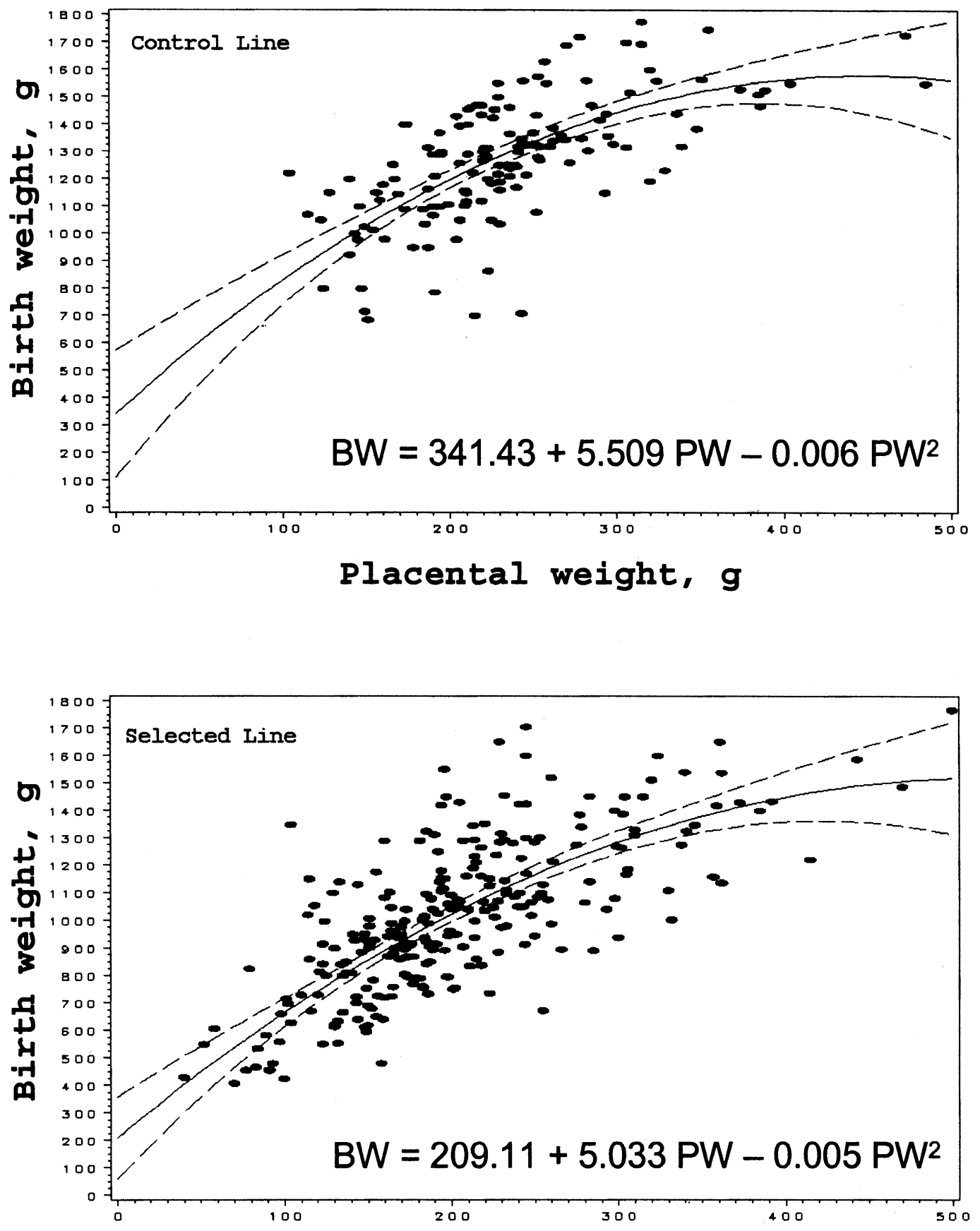

Placental weight, $g$

Figure 1. Scatter plots and quadratic regression curve ( $\pm 95 \%$ confidence limits) of the relationship between birth weight and placental weight in each of the experimental lines. Control line adjusted $R^{2}=0.49$. Selected line adjusted $\mathrm{R}^{2}=0.52$.

of embryos is more than 14 , litter size becomes dependent on uterine length (Wu et al., 1987). However, the evaluation of uterine traits in a population selected for increased LS (Gama and Johnson, 1993), and in the Meishan breed (Bazer et al., 1988) indicates that uterine dimensions in cyclic gilts may not be a good indicator of uterine capacity. Uterine measurements are needed in this population to establish whether increased uter- ine space was responsible for the increase in litter size. In addition to changes in uterine size, reduced fetal demands could be involved in the increase in uterine capacity since smaller fetuses with lower demands help to explain the higher prolificacy of the Meishan pig (Ford, 1997).

Line differences in BW and PW in the present study were due mostly to changes in LS. In the case of BW, 
this is demonstrated by the fact that the highly significant difference in favor of $\mathrm{C}$ was reduced to nonsignificant levels when adjusted for LS. Similarly, marginal differences in PW in favor of $\mathrm{C}$ disappeared when adjusted for LS. In contrast, line differences in PE in favor of $\mathrm{C}$ increased from 0.43 to 0.52 when LS was included as a covariate. This suggests that at the same LS, placentas of $\mathrm{C}$ were more efficient than placentas of $\mathrm{S}$. The fact that $\mathrm{PE}$ differences were higher when adjusted for LS also suggests that $\mathrm{C}$ could carry more piglets than $\mathrm{S}$ at the same uterine length or that proportionally bigger piglets could survive attached to placentas of similar weight. The categorical scoring procedure of PV did not give enough power to detect potential differences between the lines. The numerically higher PV score for $\mathrm{C}$ could be an indication of increased vascularity associated with an increased PE. Measurements of vascular density might allow the detection and quantification of line differences in PV in this population.

In this study, higher prolificacy likely arose from increases in both ovulation rate and uterine capacity in the selected line. The reduction in the number of mummified fetuses during the last three generations of selection suggests that in this population uterine capacity limits litter size and that further increase in prolificacy was due to an increase in uterine capacity. This uterine capacity increase in the selected line was achieved through mechanisms different from increased placental efficiency. Even more, the selected line had higher litter size despite lower placental efficiency. A single or a combination of the remaining components influencing uterine capacity may be responsible for this increase. Based on the lower birth weight of the selected line in this study, we hypothesize that one likely mechanism is a reduced fetal demand for nutrients. This hypothesis is supported by the scatter plots and regression curves presented in Figure 1. The comparison of the regression curve between lines shows that at any given placental weight, piglets are heavier in $\mathrm{C}$ than in $\mathrm{S}$. This could be explained in part by the relatively more efficient placentas in C. Alternatively, limited total nutrients available from the uterus, in combination with increased litter size, may result in a greater reduction in fetal vs placental weight, and hence, an apparent reduction in placental efficiency. An additional alternative is that selection for increased litter size may have resulted in preferential survival of slow-growing fetuses with consequently low demand for nutrients. Whether the reduction in fetal demands is mediated by the uterine environment through the placenta, the fetal genotype, or both, requires further investigation.

A second possible mechanism for the increased uterine capacity in $\mathrm{S}$ could be increased uterine space. Although reported uterine traits for the same population were similar between lines at generation 8 (Gama and Johnson, 1993), an analysis of the total piglet and placental weights carried by each female indicates that uterine space is increased in the selected line. On average, females in $\mathrm{S}$ carry $2309 \mathrm{~g}$ of piglet and $655 \mathrm{~g}$ of placenta more than females in $\mathrm{C}(P=0.01$ and $P<$ 0.01 , respectively).

The nature of the relationship between PE and PV has been questioned. Vallet (2000) proposed that the increased PE and the associated increase in PV observed in some natural and selected populations may be a function of the reduced PW and not of inherent placental function mechanisms. This is not supported by the nonsignificant correlations of PV with PW or PE observed in the present study. The negative correlation of $\mathrm{PE}$ with $\mathrm{PW}$ is in agreement with the observations of Wilson et al. (1999) and Vallet (2000).

\section{Implications}

Litter size in swine is a trait affected in a complex manner by its components and interactions among them. Different breeds and populations utilize different physiological strategies to achieve their characteristic reproductive performance. An understanding of the physiological changes resulting from successful selection for reproductive components may be useful in the design of novel selection strategies that maximize genetic progress and minimize adverse correlated responses such as a reduced birth weight and its effect on postnatal survival.

\section{Literature Cited}

Ashworth, C. J., C. S. Haley, R. P. Aitken, and I. Wilmut. 1990. Embryo survival and conceptus growth after reciprocal embryo transfer between Chinese Meishan and Landrace $\times$ Large White gilts. J. Reprod. Fertil. 90:595-603.

Bazer, F. W., A. J. Clawson, O. W. Robinson, and L. C. Ulberg. 1969. Uterine capacity in gilts. J. Reprod. Fertil. 18:121-124.

Bazer, F. W., W. W. Thatcher, F. Martinat-Botte, and M. Terqui. 1988. Sexual maturation and morphological development of the reproductive tract in Large White and prolific Chinese Meishan pigs. J. Reprod. Fertil. 83:723-728.

Bazer, F. W., W. W. Thatcher, F. Martinat-Botte, M. Terqui, M. C. Lacroix, S. Bernard, M. Revault, and D. H. Dubois. 1991. Composition of uterine flushings from Large White and prolific Chinese Meishan gilts. Reprod. Fertil. Dev. 3:51-60.

Bennett, G. L., and K. A Leymaster. 1989. Integration of ovulation rate, potential embryonic viability and uterine capacity into a model of litter size in swine. J. Anim. Sci. 67:1230-1241.

Bennett, G. L., and K. A. Leymaster. 1990. Genetic implications of a simulation model of litter size in swine based on ovulation rate, potential embryonic viability and uterine capacity: I. Genetic theory. J. Anim. Sci. 68:969-979.

Biensen, N. J., M. E. Wilson, and S. P. Ford. 1998. The impacts of either a Meishan or Yorkshire uterus on Meishan or Yorkshire fetal and placental development to days 70, 90, and 110 of gestation. J. Anim. Sci. 76:2169-2176.

Biensen, N. J., M. E. Wilson, and S. P. Ford. 1999. The impact of uterine environment and fetal genotype on conceptus size and placental vascularity during late gestation in pigs. J. Anim. Sci. 77:954-959.

Christenson, R. K. 1993. Ovulation rate and embryonic survival in Chinese Meishan and White crossbred pigs. J. Anim. Sci. 71:3060-3066.

Christenson, R. K., K. A. Leymaster, and L. D. Young. 1987. Justification of unilateral hysterectomy-ovariectomy as a model to evaluate uterine capacity in swine. J. Anim. Sci. 65:738-744. 
Fenton, F. R., F. W. Bazer, O. W. Robinson, and L. C. Ulberg. 1970. Effect of quantity of uterus on uterine capacity in gilts. J. Anim. Sci. 31:104-106.

Ford, S. P. 1995. Control of blood flow to the gravid uterus of domestic livestock species. J. Anim. Sci. 73:1852-1860.

Ford, S. P. 1997. Embryonic and fetal development in different genotypes in pigs. J. Reprod. Fertil. (Suppl.)52:165-176.

Ford, S. P., and R. K. Christenson. 1979. Blood flow to uteri of sows during the estrous cycle and early pregnancy: Local effects of the conceptus on the uterine blood supply. Biol. Reprod. 21: 617-624.

Gama, L. L. T., and R. K. Johnson. 1993. Changes in ovulation rate, uterine capacity, uterine dimension, and parity effects with selection for litter size in swine. J. Anim. Sci. 71:608-617.

Johnson, R. K., M. K. Nielsen, and D. S. Casey. 1999. Responses in ovulation rate, embryonal survival, and litter traits in swine to 14 generations of selection to increase litter size. J. Anim. Sci. 77:541-557.

Johnson, R. K., D. R. Zimmerman, W. R. Lamberson, and S. Sasaki, 1985. Influencing prolificacy of sows by selection for physiological factors. J. Reprod. Fertil. (Suppl.)33:139-149.

Knight, J. W., F. W. Bazer, W. W. Thatcher, D. E. Franke, and H. D. Wallace. 1977. Conceptus development in intact and unilaterally hysterectomized-ovariectomized gilts: Interrelations among hormonal status, placental development, fetal fluids, and fetal growth. J. Anim. Sci. 44:620-637.

Lamberson, W. R., R. K. Johnson, D. R. Zimmerman, and T. E. Long. 1991. Direct responses to selection for increased litter size, decreased age at puberty, or random selection following selection for ovulation rate in swine. J. Anim. Sci. 69:3129-3143.

Lee, G. J., M. Ritchie, M. Thomsom, A. A. Macdonald, A. Blasco, M. A. Santacreu, M. J. Argente, and C. S. Haley. 1995. Uterine capacity and prenatal survival in Meishan and Large White pigs. Anim. Sci. 60:471-479.

Leiser, R., and V. Dantzer. 1988. Structural and functional aspects of porcine placental microvasculature. Anat. Embryol. 117:409-419.
Longenecker, D. E., and B. N. Day. 1968. Fertility level of sows superovulated at post weaning estrus. J. Anim. Sci. 27:709 Day,711.

Pope, W. F. 1994. Embryonic mortality in swine. Page 53 in Embryonic Mortality in Domestic Species. M. T. Zavy and R. D. Geisert, ed. CRC Press, Boca Raton, FL.

Sibley, C. P., and R. D. H. Boyd. 1988. Control of transfer across the mature placenta. Oxf. Rev. Reprod. Biol. I10:382-435.

Vallet, J. L. 2000. Fetal erythropoiesis and other factors which influence uterine capacity in swine. J. Appl. Anim. Res. 17:1-26.

van Oijen, M. A. A. J., W. J. Koops, T. Zandstra, and B. Kemps. 1993. Modeling fetal growth in pigs. Anim. Prod. 57:447-453.

Webel, S. K., and P. J. Dziuk. 1974. Effect of stage of gestation and uterine space on prenatal survival in the pig. J. Anim. Sci. 38:960-963.

Wilcox C. J., W. W. Thatcher, and F. G. Martin. 1990. Statistical analysis of repeated measurements in physiological experiments. Page 141 in Proc. Final Res. Coord. Mtg. of the Food Agric. Org. Int. Atomic Energy Agency/ARCALIII Regional Network for Improving the Reproductive Management of Meat and MilkProducing Livestock in Latin America with the Aid of Radioimmunoassay. Int. Atomic Energy Agency, Vienna, Austria.

Wilson, M. E., N. J. Biensen, and S. P. Ford. 1999. Novel insight into control of litter size in pigs, using placental efficiency as a selection tool. J. Anim. Sci. 77:165-1658.

Wilson, M. E., N. J. Biensen, C. R. Youngs, and S. P. Ford. 1998. Development of Meishan and Yorkshire littermate conceptuses in either a Meishan or Yorkshire uterine environment to day 90 of gestation and to term. Biol. Reprod. 58:905-910.

Wu, M. C., M. D. Hentzel, and P. J. Dziuk. 1987. Relationships between uterine length and number of fetuses and prenatal mortality in pigs. J. Anim. Sci. 65:762-770.

Youngs, C. R., L. K. Christenson, and S. P. Ford. 1994. Investigations into the control of litter size in swine: III. A reciprocal embryo transfer study of early conceptus development. J. Anim. Sci. 72:725-731. 